\title{
Efeitos da aplicação de verniz contendo araçá (Psidium cattleianum, Sabine) sobre a microbiota cariogênica e a microdureza de superfície do esmalte de ratos submetidos a desafio cariogênico
}

\author{
Effects of application of varnish containing araça (Psidium cattleianum, Sabine) \\ on the cariogenic microbiota and the microhardness \\ of the enamel surface of rats submitted to cariogenic challenge
}
Efectos de la aplicación de la barniz contiendo araça (Psidium cattleianum, Sabine) sobre la microbiota cariogenica y la microdureza de la superficie del esmalte de ratones sometidos a reto cariogênico

\author{
Ellen Cristina GAETTI JARDIM ${ }^{1}$ \\ Christiane Marie SCHWEITZER ${ }^{2}$ \\ Ana Cláudia OKAMOTO ${ }^{1}$
}
Elerson GAETTI JARDIM JÚNIOR ${ }^{1}$

${ }^{1}$ Departamento de Patologia e Propedêutica Clínica, Faculdade de Odontologia, UNESP Univ. Estadual Paulista 16015-050, Araçatuba-SP, Brasil ${ }^{2}$ Departamento de Matemática, Faculdade de Engenharia, UNESP Univ. Universidade Estadual Paulista 15385-000, Ilha Solteira-SP, Brasil

\begin{abstract}
Resumo
O objetivo desse estudo foi avaliar o efeito da aplicação de um verniz contendo extrato aquoso de araçá sobre a microbiota cariogênica e a microdureza de superfície do esmalte de ratos submetidos a desafio cariogênico. Inicialmente, Streptococcus mutans ATCC 35688 foram inoculados nos ratos. Após 21 dias, os 40 ratos experimentais, divididos em 4 grupos e foram submetidos (grupos II e IV) ou não (grupos I e III) à remoção de suas glândulas salivares maiores e uso de dieta cariogênica NIH 2000 (todos os grupos), bem como à aplicação do verniz contendo o extrato vegetal (grupos I e II) ou apenas a base do verniz (grupo III e IV). O biofilme foi coletado semanalmente para avaliação da população de cocos cariogênicos. Após 56 dias, os animais foram sacrificados. Os maxilares foram inicialmente examinados segundo os critérios de Keyes, e os dentes foram submetidos à avaliação de microdureza de superfície do esmalte. A participação de estreptococos do grupo mutans no biofilme foi avaliada por meio de cultura em ágar MSBS, após incubação em condições adequadas. A análise dos dados referentes às contagens microbianas foi realizada por ANOVA, enquanto a análise da microdureza do esmalte foi submetida à análise pelo teste de Tukey, ambas com nível de significância de 5\%. Verificou-se que o esmalte dos animais que receberam o verniz com extrato de planta apresentou menores populações de cocos cariogênicos e microdureza de superfície do esmalte mais elevada do que o dos animais que receberam apenas a base do verniz.

Descritores: Agentes de Controle de Microrganismos; Psidium; Streptococcus mutans; Esmalte Dentário; Teste de Dureza.
\end{abstract}

\begin{abstract}
The aim of this study was to evaluate the effect of applying a varnish containing aqueous extract of guava on the cariogenic microbiota and microhardness of the enamel surface of rats submitted to cariogenic challenge. Initially, Streptococcus mutans ATCC 35688 were inoculated into rats. After 21 days, the 40 experimental rats were divided into 4 groups and they were submitted (Groups II and IV) or not (Groups I and III) to removal of their major salivary glands and use of cariogenic diet NIH 2000 (all groups), as well as application of the varnish containing the plant extract (Groups I and II) or only the varnish base (group III and IV). The biofilm was collected weekly to evaluate the population of cariogenic cocci. After 56 days, the animals were sacrificed. The jaws were initially examined according to the criteria of Keyes, and the teeth were subjected to evaluation of microhardness of enamel surface. The participation of Streptococcus mutans in biofilm was evaluated by culture in MSBS agar after incubation under appropriate conditions. The analysis of data on microbial counts was performed by ANOVA, while the analysis of enamel microhardness was subjected to an analysis by Tukey, both with 5\% significance level. It was found that the enamel of the animals receiving the varnish with plant extract showed smaller populations of cariogenic cocci and higher microhardness of the enamel surface than the animals that received only the varnish base.
\end{abstract}

Descriptors: Control Agents for Microorganisms; Psidium; Streptococcus mutans; Dental Enamel, Hardness Test.

\section{Resumen}

El objetivo de este estudio fue evaluar el efecto de la aplicación de un barniz que contienen extracto acuoso de la guayaba en la microbiota cariogénico y microdureza de la superficie del esmalte de los ratones sometidos a reto cariogénico. Inicialmente, Streptococcus mutans ATCC 35688 se inocularon en ratas. Después de 21 días, las 40 ratas experimentales se dividieron en 4 grupos y fueron sometidos (grupos II y IV) o no (Grupos I y III) a la eliminación de sus principales glándulas salivales y el uso de dieta cariogénica NIH 2000 (todos los grupos), así como la aplicación del barniz que contiene el extracto de la planta (Grupos I y II) o sólo la base de barniz (grupo III y IV). L biofilm se recogió semanalmente para evaluar la población de cocos cariogénico. Las mandíbulas se examinaron inicialmente de acuerdo con los criterios de Keyes, y los dientes se sometieron a evaluación de microdureza de superficie del esmalte. La participación de Streptococcus mutans en biofilm se evaluó por cultivo en agar MSBS después de la incubación en condiciones apropiadas. El análisis de los datos sobre los recuentos microbianos se realizó por ANOVA, mientras que el análisis de microdureza del esmalte se sometió a un pruebas de Tukey, tanto con el nivel de significación del 5\%. Se encontró que el esmalte de los animales que recibieron el barniz con extracto de la planta mostró poblaciones más pequeñas de cocos cariogénico y mayor microdureza de la superficie del esmalte de los animales que recibieron sólo la base de barniz.

Descriptores: Agentes de Control de Microorganismos; Psidium; Streptococcus mutans; Esmalte Dental; Pruebas de Dureza. 


\section{INTRODUÇÃO}

A cárie dentária, como a maioria dos processos patológicos que acomete a cavidade bucal, é de natureza infecciosa e, além de sua elevada prevalência, produz danos significativos ao aparelho estomatognático em função da acidificação do biofilme e perda mineral, conduzindo à perda precoce de dentes ${ }^{1}$. Essas alterações ambientais no biofilme acabam favorecendo a proliferação de microrganismos acidogênicos e acidúricos, em particular os estreptococos cariogênicos e lactobacilos ${ }^{2}$.

O desenvolvimento da cárie está intimamente associado a modificações da dieta da população ${ }^{2}$, com o aumento de carboidratos fermentáveis que favorecem o metabolismo sacarolítico ${ }^{3}$, que leva ao aumento da produção de ácidos orgânicos no biofilme, principalmente ácido lático, e que geram polissacarídeos extracelulares, que dificultam a remoção dos depósitos de diferentes origens na superfície dental e estabilizam a adesão microbiana, colaborando assim para o processo de desmineralização da hidroxiapatita e destruição das estruturas dentais ${ }^{4,5,6}$.

Fatores externos ao binômio dieta cariogênicamicrobiota também são relevantes no estabelecimento do risco à cárie e incluem diversos aspectos, como higiene, anatomia dental, composição salivar e demais fatores de susceptibilidade individual, além da utilização de medidas preventivas, como o uso de flúor, emprego de selantes e odontologia restauradora ${ }^{5,8}$. Essas condições são ainda mais potencializadas em populações que não recebem atenção odontológica preventiva precoce ${ }^{9}$.

Outro aspecto epidemiológico de relevância na cárie dentária está relacionado ao fato de que uma parcela pequena da população exposta ao risco apresenta grande parte das novas lesões cariosas, constituindo o fenômeno de polarização, o qual está presente nas populações brasileiras, e também ao redor do mundo, mostrando-se à margem das modalidades preventivas normalmente utilizadas ${ }^{10,11}$

No tratamento e prevenção de enfermidades infecciosas envolvendo o biofilme, alguns grupos étnico-culturais utilizam produtos naturais, por vezes incorporados pela indústria aos produtos de higiene bucal largamente utilizados pela população em geral. Esse é um fenômeno global e não está associado com o nível de desenvolvimento econômico da sociedade ou país, ocorrendo mesmo nas nações mais ricas e dinâmicas ${ }^{12,13}$. No Brasil, que possui uma grande diversidade cultural e muitos grupos étnicos tradicionais que ainda compartilham suas experiências no controle de processos infecciosos, e a utilização de produtos naturais pode constituir uma estratégia adicional na prevenção à cárie, principalmente junto desses grupos de polarização.
Estudos realizados por integrantes de nossos grupo de pesquisas ${ }^{14,15} \mathrm{e}$ outros autores ${ }^{16}$ evidenciaram que o gênero Psidium apresenta utilização promissora no controle do biofilme e tem se mostrado capaz de produzir extratos aquosos com elevado conteúdo de flavonoides e outros compostos fenólicos capazes de interferir com a fisiologia microbiana, diminuindo a acidogenicidade e produção de polissacarídeos extracelulares ${ }^{15}$. Esses estudos anteriores, em condições controladas, sugerem o potencial desses extratos no controle do biofilme, mas poucos são os dados do efeito dos mesmos em desafios cariogênicos em modelos animais.

A associação entre a base resinosa de verniz odontológico com o extrato aquoso de araçá (Psidium cattleianum, Sabine) mostrou atividade inibitória "in vitro" frente a cepas de referência e isolados clínicos de Streptococcus mutans, de forma a sugerir sua utilização futura na prevenção à cárie em grupos de polarização dessa enfermidade ${ }^{17}$.

Assim, considerando-se a possibilidade de utilização futura de extratos de araçá no controle do biofilme, o presente estudo objetivou avaliar a capacidade de um verniz contendo extratos de araçá em interferir na distribuição e populações de cocos cariogênicos e a microdureza de superfície do esmalte.

\section{MATERIAL E MÉTODO}

\section{- EXTRATO VEGETAL E VERNIZ}

A coleta e o preparo das folhas de Psidium cattleianum foram realizados como descrito na literatura $^{15}$, a partir de espécimes identificados segundo características de amostra previamente depositada em herbário (CPMA: Coleção de Plantas Medicinais e Aromáticas, Universidade de CampinasUNICAMP, voucher 1299). Para a obtenção do extrato aquoso a ser adicionado à base de verniz, foram empregados somente espécimes de folhas de $P$. cattleianum perfeitas e maduras, sem sinais de enfermidades ou mutilações.

No preparo do extrato, realizava-se a lavagem das folhas em água deionizada e secagem, por 24 horas, em local escuro, ventilado, na temperatura ambiente, e por 7 dias a $37^{\circ} \mathrm{C}$. Após a desidratação das folhas procedia-se a sua trituração até a obtenção de um pó. Para $100 \mathrm{~g}$ desse pó adicionavam-se $600 \mathrm{~mL}$ de água deionizada, que era mantida a $100^{\circ} \mathrm{C}$, por 5 minutos, e a $55^{\circ} \mathrm{C}$, por mais uma hora, seguido de esterilização por filtração em membranas de éster de celulose 0,22 $\mu \mathrm{m}$ (Millipore, Billerica, MA, USA).

Após o preparo, o extrato era armazenado em recipientes âmbar, a $-80^{\circ} \mathrm{C}$, até a preparação do verniz, quando se adicionavam partes iguais do extrato e da base do verniz (FGM Produtos Odontológicos Ltda, 
Joinville, SC, Brasil), constituída de resinas naturais e sintéticas.

\section{- DESAFIO CARIOGÊNICO}

Foram utilizados 40 ratos (Rattus norvegicus albinus - variedade Wistar) machos, com peso aproximado de 180 gramas, com 45 dias de idade. Os animais foram mantidos a $25^{\circ} \mathrm{C}$, em caixas comuns, realizando-se, em seguida, a análise da microbiota bucal dos ratos por meio de coletas com zaragatoas alginatadas e coletas de saliva $(0,05 \mathrm{~mL})$, com pipetas automáticas, para verificação da colonização prévia por estreptococos do grupo mutans. Os espécimes foram inoculados em ágar Mitis Salivarius Bacitracina Sacarose $^{18}$ (ágar MSBS) e mantidos, por 48 horas, em anaerobiose $\left(90 \% \mathrm{~N}_{2}+10 \% \mathrm{CO}_{2}\right)$, em dessecadores de vidro do tipo Pyrex.

A seguir, os animais foram contaminados com $10^{6}$ UFC de $S$. mutans ATCC 35688 e receberam dieta cariogênica $^{19}$ (dieta NIH 2000, com 56\% de sacarose) e água destilada esterilizada/deionizada "ad libitum" por 21 dias para estabilizar a infecção e a implantação do microrganismo no biofilme bucal ${ }^{20}$. O controle da implantação das cepas de referência na microbiota bucal dos roedores foi realizado a cada 7 dias por meio de cultura em ágar MSBS (dados préinoculação), nas condições descritas, por 3 semanas. A dieta cariogênica foi mantida durante todo o período experimental.

Após 21 dias da implantação da linhagem de $S$. mutans ATCC 35688 inoculada, os ratos foram separados em 4 grupos experimentais: Grupo I: animais que não tiveram suas glândulas salivares maiores removidas cirurgicamente, recebendo verniz acrescido do extrato de araçá; Grupo II: animais que tiveram suas glândulas salivares cirurgicamente removidas, como descrito na literatura ${ }^{21}$, recebendo verniz acrescido do extrato de araçá; Grupo III: animais que não tiveram suas glândulas salivares maiores removidas, recebendo apenas a base do verniz (sem a presença do extrato); Grupo IV: animais que tiveram suas glândulas salivares maiores removidas cirurgicamente e que receberam a base do verniz.

Os procedimentos cirúrgicos foram realizados sob anestesia por injeção de cloridrato de cetamina, na dosagem de $15 \mathrm{mg} / \mathrm{Kg}$ do animal, pela via intraperitonial, acrescida de miorrelaxante (xilosina) 15mg/Kg. Após 77 dias da inoculação da linhagem bacteriana cariogênica e 56 dias de desafio cariogênico nos grupos de roedores em condições experimentais, os animais foram sacrificados por injeção de excesso de tiopental sódico por via intra peritoneal. A seguir, as cabeças foram dissecadas, colocadas em solução fosfatada tamponada (PBS), fazendo-se, a seguir, uma avaliação quantitativa da microdureza do esmalte.
O biofilme supragengival dos roedores foi avaliado para se determinar a participação de $S$. mutans na população microbiana. A avaliação foi realizada semanalmente, desde a realização das cirurgias para remoção das glândulas salivares maiores até a eutanásia dos animais, procurando detectar para as modificações que os extratos vegetais e as condições experimentais sobre as populações de cocos acidogênicos. Adicionalmente, o peso corporal de todos os animais também era avaliado em cada coleta de espécimes clínicos.

Amostras de 0,05 g de biofilme microbiano eram removidas, com auxílio de curetas, e transferidas para meio de transporte VMGA III e diluídas em VMG $I^{22}$ e inoculadas em ágar Mitis Salivarius Bacitracina Sacarose $^{18}$. As placas foram incubadas em anaerobiose $\left(90 \% \mathrm{~N}_{2}+10 \% \mathrm{CO}_{2}\right)$, em dessecadores de vidro, a $37^{\circ} \mathrm{C}$, por 72 horas. Os isolados foram identificados de acordo com suas características morfocoloniais, morfocelulares e bioquímicofisiológicas ${ }^{18}$.

- ANÁLISE DA MICRODUREZA DE SUPERFÍCIE DO ESMALTE

A determinação da microdureza de superfície do esmalte foi realizada conforme metodologia previamente descrita ${ }^{23}$. Após o sacrifício dos animais, os incisivos dos mesmos foram removidos individualmente, enquanto os molares foram removidos em bloco. Todas as coroas dos dentes foram retiradas utilizando-se de baixa rotação com discos de corte.

Os dentes foram fixados com gaze embebida em formol a $2 \%$, inseridos em blocos de resina acrílica. $\mathrm{O}$ desgaste foi realizado sob baixa rotação e refrigeração, até a exposição da superfície de esmalte, seguido de polimento dos dentes com uma sequência de lixas e refrigeração a água. Entre cada polimento, os blocos foram lavados com jatos de água deionizada e submetidos a ultra-som Branson 2210, em água deionizada durante 3 minutos. Na sequência o esmalte foi polido com papel feltro e suspensão de diamante. Os corpos de provas foram lavados com jato de água deionizada e submetidos ao ultrassom e lavados, novamente, com jatos de água deionizada, e conservados em ambiente úmido (gazes embebidas em formol a $2 \%$ ).

Em cada incisivo, na região cervical, foram realizadas 4 endentações no esmalte, utilizando-se carga de 25 gramas e tempo de 10 segundos, separadas por uma distância de $10 \mu \mathrm{m}$ em relação à superfície de esmalte e $20 \mu \mathrm{m}$ entre si. Nos "blocos" de molares, escolheu-se o fundo de sulco oclusal do segundo molar, onde foram realizadas 4 endentações no esmalte (Microdureza Superficial Inicial - MDSI), utilizando-se carga de 25 gramas e o tempo de 10 
segundos, separadas por uma distância de $10 \mu \mathrm{m}$ em relação à superfície de esmalte e, as demais, $20 \mu \mathrm{m}$ entre si.

\section{- ANÁLISE ESTATÍSTICA}

Os resultados obtidos referentes à população de cocos cariogênicos nos grupos experimentais foram analisados por meio de análise de variância (ANOVA) pelo teste de Mann-Whitney, enquanto os dados referentes à microdureza do esmalte dos dentes dos animais foram analisados estatisticamente pelo Teste de Tukey, com nível de significância de 5\%.

\section{RESULTADOS}

A realização da cirurgia de remoção das glândulas salivares maiores dos ratos constituiu procedimento cirúrgico complexo, em particular para a glândula parótida, visto que a mesma atinge grandes dimensões e envolve estruturas anatômicas nobres no rato. Contudo, as perdas de animais experimentais em função desses procedimentos cirúrgicos foram muito baixas, tendo sido registrado em apenas um espécime animal, o qual foi imediatamente substituído. No presente estudo, conseguiu-se a implantação da cepa de referência na boca de todos os ratos.

A remoção cirúrgica das glândulas salivares maiores colaborou para o aumento das populações de cocos cariogênicos nos animais experimentais. Os animais submetidos à remoção cirúrgica das glândulas salivares maiores, independentemente de terem recebido a base de verniz ou a associação verniz/extrato, apresentaram níveis mais elevados de cocos cariogênicos ao longo de todo o experimento $(\mathrm{p}<0,01)$.

A avaliação da presença de cáries nas superfícies lisas e nas fóssulas e fissuras dos ratos mostrou resultados modestos, em cada animal, mesmo no grupo dos ratos dessalivados, apresentando de 1 a 3 lesões cariosas, o que não permitiu que a análise estatística utilizasse esses dados para avaliação de significância. Optou-se, então por enfatizar as perdas minerais sofridas pelo esmalte dos ratos nas diferentes condições experimentais, como apresentado na Tabela 1. Verificou-se que os animais tratados com a associação extrato de $P$. catteianum/verniz apresentaram microdureza superficial do esmalte superior ao grupo que recebeu apenas a base do verniz ( $\mathrm{p}=0,0127$ ), não se observando diferenças entre os dentes posteriores e os incisivos.

Tabela 1. Porcentagem de volume mineral do esmalte (média \pm desvio padrão) dos dentes dos animais não operados e dessalivados de acordo com o grupo experimental.

\begin{tabular}{lcccc}
\hline \multirow{2}{*}{ Tratamento } & \multicolumn{3}{c}{ Não Operados } & \multicolumn{2}{c}{ Dessalivados } \\
\cline { 2 - 5 } & incisivo & molar & incisivo & molar \\
\hline Verniz e Araçá & $96,5 \pm 0,2$ & $93,3 \pm 0,2$ & $91,2 \pm 0,4$ & $93,2 \pm 0,1$ \\
Base do Verniz & $86,1 \pm 0,4$ & $88,2 \pm 0,1$ & $85,2 \pm 0,4$ & $82,3 \pm 0,1$ \\
\hline
\end{tabular}

Quando se compara o nível de colonização pela cepa de referência nos animais dos diferentes grupos experimentais, verifica-se que houve uma diminuição do número de unidades formadoras de colônias desses cocos após a aplicação da base do verniz e também do verniz com extrato, sendo que o verniz com extrato produziu uma redução mais significativa da contaminação pelos estreptococos acidogênicos $(\mathrm{p}<0,05)$.

Observou-se diminuição na contagem das unidades formadoras de colônias de cocos cariogênicos com a aplicação de verniz com extrato com araçá, tanto no grupo dos ratos operados como no grupo dos ratos não operados $(\mathrm{p}<0.05)$, sendo que os animais operados apresentaram níveis mais elevados de $S$. mutans $(\mathrm{p}<0,01)$. O número de cocos cariogênicos atingiu seus maiores valores logo antes da aplicação da base do verniz e da associação verniz/extrato, sofrendo uma redução significativa em todos os grupos a partir desse momento (Figura 1).

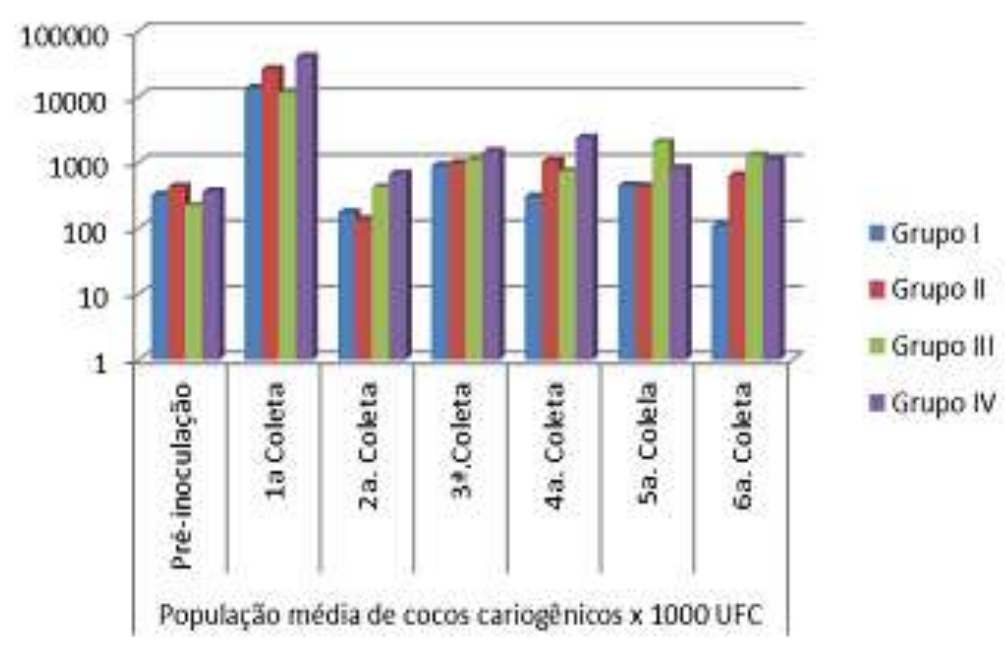

Figura 1. Evolução da população de cocos cariogênicos nos grupos experimentais

Os animais mostraram, independentemente do grupo experimental, ganho de peso semelhante, até da data do sacrifício, de forma que a adição da base de verniz e de sua associação com o extrato de araçá não afetou o ganho de peso corporal dos animais.

\section{DISCUSSÃO}

A descoberta de métodos e substâncias que auxiliem no controle do desenvolvimento desses biofilmes cariogênicos se torna importante para o controle e prevenção da cárie dentária ${ }^{10,15,17}$, particularmente em função da existência dos grupos de polarização que não respondem satisfatoriamente às medidas preventivas tradicionais ${ }^{10,11,24,25}$.

O uso de agentes antimicrobianos para o controle do biofilme esbarra em sérias limitações, que vão desde a maior resistência que esses microrganismos apresentam quando comparados com bactérias planctônicas ${ }^{17,26}$, dificuldade de penetração do princípio ativo no interior do biofilme ${ }^{27}$, alterações metabólicas bacterianas ${ }^{27,28}$, além dos efeitos 
colaterais dos principais agentes químicos e da falta de biodisponibilidade $^{29}$, a qual pode ser parcialmente contornada pela incorporação do princípio ativo no interior de uma matriz ou sistema de liberação lenta, como o emprego de verniz que é capaz de permitir a saturação ou o contato prolongado com o metabolismo celular microbiano.

Muito interesse vem sendo dispensado ao estudo do efeito de compostos naturais sobre infecções endógenas humanas ${ }^{30,31}$, particularmente sobre o biofilme bucal e seus impactos na ecologia microbiana $^{32}$ e sobre a cárie dentária ${ }^{12,13}$. Dentre os extratos naturais que tiveram sua atividade inibitória estudada destacam-se o chá-verde japonês ${ }^{33}$,

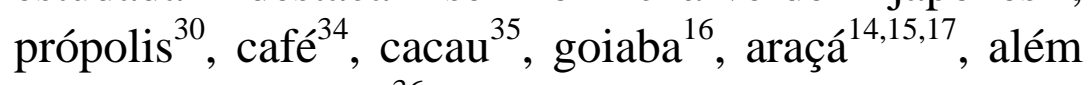
de mate e chá preto ${ }^{36}$.

Os ensaios sobre a atividade antimicrobiana do verniz testado sobre os isolados e cepas de $S$. mutans evidenciaram que o mesmo foi capaz de inibir todos os isolados testados ${ }^{17}$, e como a solubilidade da base do verniz é baixa, reduzindo a difusão dos princípios ativos do extrato de araçá, pode-se ter mais tempo de contato entre os princípios com atividade antimicrobiana e o biofilme.

No presente estudo, para os ensaios com animais experimentais, empregou-se a metodologia descrita por Keyes ${ }^{37,38}$, com animais que recebiam uma dieta rica em sacarose (56\% de açúcar - dieta NIH 2000). Contudo, poucas discretas lesões cavitadas puderam ser observadas em alguns animais, mesmo entre os animais dessalivados. A despeito do pequeno número lesões cavitadas de cárie clinicamente detectáveis, pode-se considerar que o desafio cariogênico descrito no presente estudo foi satisfatório, visto que a resposta do esmalte dental ao processo de desmineralização se inicia muito antes de uma cavidade se tornar clinicamente detectável e verificou-se uma redução significativa da microdureza superficial do esmalte dental, particularmente no grupo dos ratos dessalivados.

A utilização de modelos animais para avaliação de medidas preventivas da cárie dentária ou para determinação de fatores interferentes é universalmente aceita $^{32}$, a despeito das limitações do desse modelo de estudo, quer por aspectos de anatomia dental e do aparelho estomatognático, até por aspectos referentes à dieta e microbiota bucal. A literatura ${ }^{20,21}$ traz que a remoção das glândulas salivares maiores de ratos pode exacerbar o desafio cariogênico, com a subsequente formação de áreas de desmineralização e cavitação.

A redução dos níveis de $S$. mutans observado com o emprego do verniz e da associação podem ter se dado pela redução no próprio acúmulo do biofilme nos primeiros dias após a aplicação dos mesmos, visto que a base do verniz é inerte, não apresentando capacidade de inibir o crescimento bacteriano. Daglia et al. $^{39}$ sugeriram que alguns extratos de plantas poderiam inibir a adesão microbiana modificando também as adesinas bacterianas o que dificultaria o reconhecimento entre essas estruturas protéicas e aqueles receptores presentes na película adquirida, uma vez que esse processo apresenta especificidade. Os extratos vegetais também poderiam competir com as adesinas pela ligação aos receptores do hospedeiro, ou mesmo terem afinidade recíproca, uma vez que parte das adesinas bacterianas se comporta como lectinas (as quais possuem afinidade por receptores que contenham carboidratos na sua estrutura), de forma que glicoproteínas do extrato poderiam ter o efeito acima mencionado.

A literatura também relata que o extrato de araçá possui a capacidade de reduzir significativamente a acidogenicidade e produção de polissacarídeos extracelulares em Streptococcus mutans $^{14}$, o que pode colaborar para reduzir a participação desses cocos cariogênicos no biofilme dos animais tratado com a associação entre verniz e extrato de araçá. Adicionalmente, pode-se verificar que o espectro de ação do extrato sobre a microbiota e demais sistemas biológicos é amplo, incluindo não apenas microrganismos Gram-negativos entéricos, cocos Gram-positivos, leveduras e até células neoplásicas malignas ${ }^{40}$, possivelmente pela elevada quantidade de compostos fenólicos com atividade antibacteriana $^{15,40}$. Deve-se ressaltar que o araçá não possui níveis significativos de fluoretos, cálcio ou fosfato, de forma que, aparentemente, não interfere diretamente no processo de remineralização dental, mas é capaz de interferir com a fisiologia microbiana, reduzindo a acidogenicidade e a síntese de polímeros extra e intracelulares, alterando a composição microbiana do biofilme.

\section{CONCLUSÃO}

Os resultados obtidos mostram que a associação verniz e extrato aquoso de araçá é capaz de interferir significativamente com a microbiota cariogênica do biofilme em ratos submetidos a desafio cariogênico, bem como modificar a microdureza superfical do esmalte dental desses, sem interferir com o ganho de peso dos roedores.

\section{AGRADECIMENTOS}

Os recursos para a realização desse estudo foram obtidos como parte de projeto junto à Fundação de Amparo à Pesquisa do Estado de São Paulo (FAPESP, proc. 2005/56218-8).

\section{REFERÊNCIAS}

1. García-Cortés JO, Medina-Solí CE, LoyolaRodriguez JP et al. Dental caries`s experience, prevalence and severity in Mexican adolescents 
and young adults," Rev Salud Pública. 2009;11(1):82-91.

2. Smith EG, Spatafora GA. Gene regulation in $S$. mutans: complex control in a complex environment. J Dent Res. 2012;91(2):133-41.

3. Costalonga M, Herzberg MC. The oral microbiome and the immunobiology of periodontal disease and caries. Immunol Lett. 2014;162(2 Pt A):22-38.

4. Smith DJ, Mattos-Graner RO. Secretory immunity following mutans streptococcal infection or immunization. Curr Top Microbiol Immunol. 2008;319:131-56.

5. Bennadi D, Reddy V, Kshetrimayum N. Influence of genetic factor on dental caries. Ind J Res Pharm Biotech. 2014;2(3):1196-1207.

6. Takashima Y, Fujita K, Ardin AC, Nagayama K, Nomura R2, Nakano K, Matsumoto-Nakano M. Characterization of the dextran-binding domain in the glucan-binding protein $\mathrm{C}$ of Streptococcus mutans. J Appl Microbiol. 2015;119(4):1148-57.

7. Pienihäkkinen K, Jokela J. Clinical outcomes of risk-based caries prevention in preschool-aged children. Commun Dent Oral Epidemiol. 2002;30(2):143-50.

8. Thenisch NL, Bachmann LM, Imfeld T, Leisebach Minder T, Steurer J. Are mutans streptococci detected in preschool children a reliable predictive factor for dental caries risk? A systematic review. Caries Res. 2006;40(5):366-74.

9. Langendijk-Genevaux PS, Grimm WD, van der Hoeven JS. Sulfate-reducing bacteria in relation with other potential periodontal pathogens. J Clin Periodontol. 2001;28(12):1151-7.

10. Narvai PC, Frazão P, Roncalli AG, Antunes JLF. Cárie dentária no Brasil: declínio, polarização, iniquidade e exclusão social. Rev Panam Salud Publica. 2006;19(6):385-93.

11. Tanner T, Kämppi A, Päkkilä J, Patinen P, Rosberg J, Karjalainen K, Järvelin M-R, Tjäderhane L, Anttonen V. Prevalence and polarization of dental caries among young, healthy adults: cross-sectional epidemiological study. Acta Odontol Scand. 2013;71(6):1436-42.

12. Azizi A, Aghayan S, Zaker S, Shakeri M, Entezari $\mathrm{N}$, Lawaf S. In vitro effect of zingiber officinale extract on growth of Streptococcus mutans and Streptococcus sanguinis. Int J Dent. 2015. Doi 10.1155/2015/489842

13. Cheng L, Li J, He L, Zhou X. Natural products and caries prevention. Caries Res. 2015;49(Suppl1):38-45.

14. Brighenti FL, Luppens SBI, Delbem ACB, Deng DM, Hoogenkamp MA, Gaetti-Jardim Jr E, Dekker HL, Crielaard W, ten Cate JM. Effect of Psidium cattleianum leaf extract on Streptococcus mutans viability, protein expression and acid production. Caries Res. 2008;42(2):148-54.

15. Brighenti FL, Gaetti-Jardim Jr E, Danelon M, Evangelista GV, Delbem ACB. Effect of Psidium cattleianum leaf extract on enamel demineralisation and dental biofilm composition in situ. Arch Oral Biol. 2012;57(8):1034-40.

16. Prabu GR, Gnanamani A, Sadulla S. Guaijaverin a plant flavonoid as potential antiplaque agent against Streptococcus mutans. J Appl Microbiol. 2006;101(2):487-95.

17. Gaetti-Jardim EC, Gaetti-Jardim Jr E, Schweitzer CM, Okamoto AC. Atividade inibitória do verniz de araçá (Psidium cattleianum Sabine) sobre amostras de Streptococcus mutans "in vitro". Arch Health Invest. 2015;4(6):54-60.

18. Gold OG, Jordan HV, Van Houte J. A selective medium for Streptococcus mutans. Arch Oral Biol. 1973;18(11):1357-64.

19. Hamada S, Ooshima T, Torii M, Imanishi $H$, Masuda N, Sobue S, et al. Dental caries induction in experimental animals by clinical strains of Streptococcus mutans isolated from Japanese children. Microbiol Immunol. 1978;22(6):301-4.

20. Peres RC, Coppo LC, Franco EM, Volpato MC, Groppo FC, Rosalen PL. Cariogenicity of different types of milk: an experimental study using animal model. Braz Dent J. 2002;13(1):27-32.

21. Bowen W, Madison KM, Young DA. The effect of desalivation on coronal and root surface caries in rats. J Dent Res. 1988;67(1):21-3.

22. Möller AJ. Microbiol examination of root canals and periapical tissues of human teeth: methodological studies. Odontol Tidskr. 1966;74(Suppl):1-138.

23. Shinoda H. Effect of long-term administration of fluoride on physico-chemical properties of the rat incisor enamel. Calcif Tissue Res. 1975;18(2):91100 .

24. Gushi LL, Soares MC, Forni TIB, Vieira V, Wada RS, Sousa MLR. Cárie dentária em adolescentes de 15 a 19 anos de idade no estado de São Paulo, Brasil, 2002. Cad Saúde Pública. 2005;21(5):1383-91.

25. Martins RJ, Garbin CAS, Garbin AJI, Moimaz SAS, Saliba O. Declínio da cárie em um município da região noroeste do estado de São Paulo, Brasil, no período de 1998 a 2004. Cad Saúde Pública 2006;22(5):1035-41.

26. Landry RM, An D, Hupp JT, Singh PK, Parsek MR. Mucin-Pseudomonas aeruginosa interactions promote biofilm formation and antibiotic resistance. Mol Microbiol. 2006;59(1):142-51.

27. Marsh PD. Dental Plaque as a microbial biofilm. Caries Res. 2004;38(3):204-11.

28. Guggenheim B, Guggenheim M, Gmür R, Giertsen E, Thurnheer T. Application of the 
Zürich biofilm model to problems of cariology. Caries Res. 2004;38(3):212-22.

29. Bruschi ML, Panzeri H, Freitas O, Lara EHG, Gremião MPD. Sistemas de liberação de fármaco intrabolsa periodontal. Rev Bras Cienc Farm. 2006;42(1):29-47.

30. Leitão DPS, Silva Filho AA, Polizello ACM, Bastos JK, Spadaro ACC. Comparative evaluation of in-vitro effects of Brazilian green propolis and Baccharis dracunculifolia extracts on cariogenic factors of Streptococcus mutans. Biol Pharm Bull. 2004;27(11):1834-9.

31. Takarada K, Kimizuka R, Takahashi N, Honma K, Okuda K, Kato T. A comparison of the antibacterial efficacies of essential oils against oral pathogens. Oral Microbiol Immunol. 2004;19(1):61-4.

32. Ozaki F, Pannuti CM, Imbronito AV, Pessotti W, Saraiva L, Freitas NM, et al. Efficacy of a herbal toothpaste on patients with established gingivitis a randomized controlled tria. Braz Oral Res. 2006;20(2):172-7.

33. Otake S, Makimura M, Kuroki T, Nishihara Y, Hirasawa M. Anticaries effects of polyphenolic compounds from Japanese green tea. Caries Res. 1991;25(6):438-43.

34. Landucci LF, Oliveira LD, Brandão EHS, KogaIto CY, Gaetti-Jardim Jr E, Jorge AO. Efeitos de Coffea arabica sobre a aderência de Streptococcus mutans à superfície de vidro. Ciênc Odontol Bras. 2003;6(3):58-64.

35. Matsumoto M, Tsuji M, Okuda J, Sasaki H, Nakano K, Osawa K, et al.. Inhibitory effects of cacao bean husk extract on plaque formation in vitro and in vivo. Eur J Oral Sci. 2004;112(3):24956.

36. Gaetti-Jardim Jr E, Landucci LF, Okamoto AC, Akeshigue H. Antimicrobial activity of plants infusions on oral fusobacteria and their adherence to human erythrocytes. Arch Health Invest. 2013;2(1):3-9.

37. Keyes PH. Dental caries in the molar teeth of ratsI. Distribution of lesions induced by highcarbohydrate low-fat diets. J. Dent Res. 1958;37(6):1077-87.

38. Keyes, P.H. Dental caries in the molar teeth of rats- II. A method for diagnosing and scoring several types of lesions simultaneously. J. Dent Res. 1958;37(6):1088-99.

39. Daglia M, Tarsi R, Papetti A, Grisoli P, Dacarro C, Pruzzo C, et al. Antiadhesive effect of green and roasted coffee on Streptococcus mutans adhesive properties on saliva-coated hydroxyapatite beads. J. Agric Food Chem. 2002;50(5):1225-9.
40. Medina AL, Haas LIR, Chaves FC, Salvador M, Zambiazi RC, Silva WP, Nora L, Rombaldi CV. Araça (Psidium cattleianum Sabine) fruit extracts with antioxidant and antimicrobial activities and antiproliferative effect on human cancer cells. Food Chem. 2011;128 (4):916-22.

\section{CONFLITO DE INTERESSES}

Os autores declaram não haver conflitos de interesse.

\section{AUTOR PARA CORRESPONDÊNCIA}

\section{Ana Cláudia Okamoto}

aokamoto@foa.unesp.br 